\title{
IMPACTO DA GESTÃO DA TECNOLOGIA NA QUALIDADE DE VIDA DE ESTUDANTES: ESTUDO DE CASO EM ESCOLAS TÉCNICAS DO ESTADO DE SÃO PAULO
}

\section{ARTIGO ORIGINAL}

RAMIREZ, Alejandro Lynn Pereira ${ }^{1}$, SANTOS, Fabiano Marcelo dos², GERALDI, Luciana Maura Aquaroni ${ }^{3}$

RAMIREZ, Alejandro Lynn Pereira. SANTOS, Fabiano Marcelo dos. GERALDI, Luciana Maura Aquaroni. Impacto da gestão da tecnologia na qualidade de vida de estudantes: estudo de caso em escolas técnicas do estado de São Paulo. Revista Científica Multidisciplinar Núcleo Do Conhecimento. Ano 06, Ed. 06, Vol. 10, pp. 05-19. Junho De 2021. ISSN: 2448-0959, Link De Acesso: https://www.nucleodoconhecimento.com.br/educacao/vida-de-estudantes, $\quad$ DOI: 10.32749/nucleodoconhecimento.com.br/educacao/vida-de-estudantes

\footnotetext{
${ }^{1}$ Mestrado em Administração, Pós-graduação em Comércio Exterior e Graduação em Administração pela Universidade Paulista.

${ }^{2}$ Bacharel em Engenharia pela Universidade São Judas.

${ }^{3}$ Orientadora. Doutorado em Educação Escolar pela Unesp, Mestrado em Engenharia (Engenharia de Produção) pela Universidade de São Paulo, pós-graduação em Didática (2005) e Informática aplicada à Educação Matemática (2008) pela Faculdade São Luís de Jaboticabal e graduação em Tecnologia em Processamento de Dados pela Faculdade de Tecnologia de Taquaritinga.
}

RC: 88707

Disponível em: https://www.nucleodoconhecimento.com.br/educacao/vida-de-estudantes 


\section{RESUMO}

Esta pesquisa teve como objetivo analisar como a gestão da tecnologia contribui para a melhora da qualidade de vida de alunos das escolas do ensino técnico na cidade de São Paulo em conformidade com uma das metas estabelecidas pela ONU (Organização das Nações Unidas) que promove vida saudável e bem-estar para as pessoas do mundo. A pergunta que direcionou a pesquisa foi: é possível que a Gestão da Tecnologia melhore a qualidade de vida de alunos durante uma crise sanitária? A relevância desta pesquisa está nas informações obtidas sobre a percepção de melhora da qualidade de vida de alunos pela efetiva gestão dos recursos tecnológicos no período da crise sanitário-econômica em 2020 e pela verificação da possibilidade de continuação da modalidade remota no ensino técnico após a pandemia. A pesquisa foi qualitativa e o fenômeno da gestão de tecnologia que leva à qualidade de vida foi observado com a utilização do estudo de caso de escolas de ensino técnico (ETEC) na cidade de São Paulo - Brasil. Verificamos que a Gestão da Tecnologia leva à Qualidade de Vida, no entanto, os alunos não têm consciência de que a possibilidade de uma carreira, crescimento pessoal e perspectiva de avanço na vida profissional são indicadores de melhora na qualidade de vida.

Palavras-Chave: Gestão, Tecnologia, Qualidade de vida, Ensino técnico, Educação.

\section{INTRODUÇÃO}

Durante a crise sanitária de 2019 e 2020 muitas organizações se viram na obrigação imediata de inovar para minimizar os efeitos devastadores de uma pandemia e manter o foco em seus objetivos. As organizações buscam Vantagem Competitiva (PORTER, 1985) e Qualidade de Vida (WALTON, 1973) através da gestão efetiva dos diversos recursos como a tecnologia conforme Barney (1991).

Esta pesquisa tem como objetivo geral analisar como a gestão da tecnologia contribui para a melhora da qualidade de vida de alunos de escolas do ensino técnico na cidade RC: 88707

Disponível em: https://www.nucleodoconhecimento.com.br/educacao/vida-de-estudantes 
de São Paulo - ETEC. A pergunta de pesquisa foi: é possível que a Gestão da Tecnologia melhore a qualidade de vida de alunos durante uma crise sanitária? Para responder esta pergunta foi realizada: 1) revisão da literatura sobre Gestão e Tecnologia aplicadas ao ensino técnico na cidade de São Paulo e; 2) elaboração e aplicação de um questionário aos alunos para analisar qualitativamente se eles tiveram melhor qualidade de vida no período da crise sanitária de 2019/2020.

Este trabalho pode ser justificado pela atual relevância das técnicas de administração (CHIAVENATO, 2010) utilizadas na gestão de tecnologias aplicadas no aprendizado por algumas escolas (CHAVES, 1998) e que podem levar qualidade de vida aos alunos (EVANS, 1996). Ainda, este trabalho é relevante pela obtenção de informações sobre a atual situação dos alunos frente aos recursos tecnológicos utilizados no período da crise sanitário-econômica iniciada no Brasil em 2020 e sobre a possibilidade de continuidade da modalidade remota no ensino técnico.

Por meio da literatura sobre Gestão Tecnológica e Qualidade de Vida foi possível observar que a Tecnologia pode proporcionar melhores condições de Qualidade de Vida aos alunos, pois a aprendizagem de uma ferramenta tecnológica em ampla utilização no mercado de trabalho pode trazer grandes possibilidades de acesso a processos seletivos e vagas de empregos em empresas que estão utilizando novas tecnologia de seleção e trabalho remoto. Este fenômeno pode ser observado nas escolas técnicas de São Paulo as quais a Gestão da Tecnologia foi aplicada à aprendizagem levando Qualidade de Vida a milhares de alunos e em conformidade com o ODS 3 - Saúde e Bem-estar - 3.4 "promover a saúde mental e o bem-estar" (ONU, 2020). O aluno aprende e utiliza as mesmas ferramentas tecnológicas, na sua vida escolar, que serão utilizadas nas empresas para processos seletivos e no trabalho remoto.

RC: 88707

Disponível em: https://www.nucleodoconhecimento.com.br/educacao/vida-de-estudantes 
Nos próximos itens abordaremos a Gestão, a Tecnologia, a Qualidade de Vida, os Métodos utilizados na pesquisa, a Discussão dos Resultados obtidos e as Considerações Finais.

\section{FUNDAMENTAÇÃO TEÓRICA}

\subsection{A GESTÃO E A QUALIDADE DE VIDA}

Os estudos sobre a Gestão ou Administração de empresas tiveram seu início num período de mudanças no mundo no início do século XX. Os difíceis tempos para a sociedade que viveu o período da Revolução Industrial impulsionaram os estudos científicos sobre Administração de Empresas (VIZEU, 2010). As empresas na sociedade comercial de Smith, descrita em Riqueza das Nações (1996 [1776], vs. I e II), buscavam e continuam buscando vantagem competitiva (Porter,1985) e Qualidade de Vida (WALTON, 1973; CHIAVENATO, 2010). Semelhantemente, em 2019 e 2020, durante a crise sanitária, as empresas e outras organizações passaram a ser observadas por pesquisadores para verificar como elas reagem para manter a busca por vantagem competitiva e Qualidade de Vida (SILVA, 2020).

Para alcançar vantagem competitiva e Qualidade de Vida as organizações utilizam seus recursos e capacidades controlados que são difíceis de ser imitado, dado o alto custo de aquisição ou para serem desenvolvidos (BARNEY; HESTERLY, 2011). Barney (1991) explica que, o recurso de uma empresa deve ser valioso (explorar as oportunidades da empresa), raro entre as empresas que competem, inimitável, e não deve haver um substituto desse recurso valioso, raro e inimitável. A Gestão efetiva de uma organização em conjunto com a utilização de uma ferramenta tecnológica pode ser considerada como um recurso raro e de difícil imitação.

A crise sanitária que iniciou em 2019 e se estendeu por 2020 levou as organizações privadas e públicas a aplicarem técnicas de Gestão de maneira efetiva para se adaptarem e manterem a busca por vantagem competitiva e Qualidade de Vida de RC: 88707

Disponível em: https://www.nucleodoconhecimento.com.br/educacao/vida-de-estudantes 
seus membros. As escolas também podem ser entendidas como organizações que buscam vantagem competitiva sobre outras escolas e Qualidade de Vida para seus funcionários, professores e alunos (ALPERSTEDT; MARTIGNAGO e FIATES, 2006). Assim, com a utilização da Gestão efetiva de organizações como as escolas técnicas é possível alcançar vantagem competitiva e Qualidade de Vida para as pessoas que as compõem.

\subsection{A TECNOLOGIA E A QUALIDADE DE VIDA}

Quando observada, a tecnologia não aparenta ter grande relação com qualidade de vida, porém numa sociedade contemporânea, elas caminham paralelamente. Não obstante, uma sociedade necessita ter conhecimento e utilizá-lo na resolução de problemas, a fim de obter saúde, alimentação, trabalho, lazer, segurança e um meio ambiente adequado (SILVA e MELO, 2001).

Para Silva e Melo (2001, p. 84) que afirmam que para atingir um aumento sustentável na qualidade de vida de uma sociedade, faz-se necessário o crescimento econômico e a elevação da capacidade de geração de riqueza; entretanto, a escaldada econômica não é obstante para corrigir indiferenças sociais trazidas ao longo do tempo. Também não tem capacidade de distribuir igualitariamente seus benefícios trazidos do desenvolvimento, independente se for regional ou social. Da forma que a sociedade atual se apresenta concentrada em grandes centros urbanos, desequilíbrio na parte nutricional, uso excessivo de agrotóxico nos alimentos, sociedade dividida e excluindo as minorias, serviços públicos a quem do desejado, precariedade e falta de habitação, meio ambiente sobrecarregado pelas taxas de poluição que provem de grandes centros econômicos, culminou na degradação da qualidade de vida, mesmo nos países com mais recursos.

Atualmente, conhecimento e inovação são fundamentais e imprescindíveis no andamento do desenvolvimento econômico. Os três conhecidos fatores de produção, capital, trabalho e recursos naturais, devem deixar de ser explorados para que não RC: 88707

Disponível em: https://www.nucleodoconhecimento.com.br/educacao/vida-de-estudantes 
gerem impactos na cadeia ambiental e sustentável e os países com economias mais avantajadas começam a ter uma diminuição na produtividade do trabalho de uma forma relativa. Entendendo todo esse processo, acumular conhecimento não é suficiente, pois existe a necessidade da aplicação desse conhecimento na solução da problemática enfrentada, e também a capacidade de inovar gerando novos processos a fim de otimizar os recursos já existentes, gerar novas oportunidades e não só produzir, mas também distribuir a riqueza, e por fim, mas não menos importante, fomentar o bem-estar (SILVA e MELO, 2001).

\subsection{A QUALIDADE DE VIDA}

A qualidade de vida tem sido alvo frequente de estudos em Administração de Empresas (WALTON, 1973; CHIAVENATO, 2010; ALBUQUERQUE e LIMONGIFRANÇA, 1998; EVANS, 1996; LÍRIO; GALLON e COSTA, 2020). Conhecida como (QVT) Qualidade de Vida no Trabalho, o construto pode ser entendido como as ações que uma organização realiza para propiciar o desenvolvimento de um indivíduo durante e após a permanência dele numa organização (LÍRIO; GALLON E COSTA, 2020). Assim, uma instituição que oferece educação profissional também pode ser entendida como uma organização que leva ou não em consideração a qualidade de vida de funcionários e alunos que a compõe.

Tiecher e Diehl (2017) apontam que a QVT também é a percepção do indivíduo sobre o seu bem-estar dentro e fora da organização levando em consideração o seu estado físico, social, espiritual entre outras maneiras de percepção sobre sentir-se bem. Para estes autores, o indivíduo satisfeito com o seu bem-estar produz mais, com mais qualidade e por mais tempo.

Walton (1973) desenvolveu um método de avaliação de QVT com base no bem-estar do ser humano e na responsabilidade social e considerou as condições que a organização oferece ao indivíduo pertencente a ela e aspectos relacionados ao poder que a organização exerce sobre os seus integrantes. Foram definidas oito dimensões RC: 88707

Disponível em: https://www.nucleodoconhecimento.com.br/educacao/vida-de-estudantes 
e os indicadores de cada uma delas conforme o Quadro 1. O modelo pode ser aplicado levando em consideração todas as dimensões com seus indicadores, mas também pode ser utilizado para analisar algumas das oito dimensões da QVT.

Quadro 1 - Dimensões de QVT segundo o modelo de Walton (1973).

\begin{tabular}{|c|c|}
\hline Dimensões & Indicadores de QVT \\
\hline $\begin{array}{l}\text { 1. Compensação justa e } \\
\text { adequada }\end{array}$ & $\begin{array}{l}\text { Equidade interna e externa; justiça na } \\
\text { compensação; partilha dos ganhos de } \\
\text { produtividade; e proporcionalidade entre salários. }\end{array}$ \\
\hline 2. Condiç & $\begin{array}{l}\text { Jornada de trabalho razoável; ambiente físico } \\
\text { seguro e saudável; e ausência de insalubridade. }\end{array}$ \\
\hline $\begin{array}{l}\text { 3. Uso e desenvolvimento } \\
\text { de capacidades }\end{array}$ & $\begin{array}{l}\text { Autonomia; autocontrole relativo; e qualidades } \\
\text { múltiplas. }\end{array}$ \\
\hline $\begin{array}{l}\text { 4. Oportunidade de } \\
\text { crescimento e segurança }\end{array}$ & $\begin{array}{l}\text { Possibilidade de carreira; crescimento pessoal; } \\
\text { perspectiva de avanço salarial; e segurança de } \\
\text { emprego. }\end{array}$ \\
\hline $\begin{array}{l}\text { Integração social na } \\
\text { organização }\end{array}$ & $\begin{array}{l}\text { Ausência de preconceitos; igualdade; mobilidade; } \\
\text { relacionamento; e senso comunitário. }\end{array}$ \\
\hline nalis & $\begin{array}{l}\text { Direitos de proteção do trabalhador; privacidade } \\
\text { pessoal; liberdade de expressão; tratamento } \\
\text { imparcial; e direitos trabalhistas. }\end{array}$ \\
\hline $\begin{array}{l}\text { 7. O trabalho e o espaço } \\
\text { total de vida }\end{array}$ & $\begin{array}{l}\text { Papel balanceado no trabalho; estabilidade de } \\
\text { horários; poucas mudanças geográficas; e tempo } \\
\text { de lazer da família. }\end{array}$ \\
\hline $\begin{array}{l}\text { 8. Relevância social do } \\
\text { trabalho na vida }\end{array}$ & $\begin{array}{l}\text { Imagem da empresa; responsabilidade social da } \\
\text { empresa; responsabilidade pelos produtos; e } \\
\text { práticas de emprego. }\end{array}$ \\
\hline
\end{tabular}

Fonte: LÍRIO, GALLON E COSTA (2020)

RC: 88707

Disponível em: https://www.nucleodoconhecimento.com.br/educacao/vida-de-estudantes 
Para uma instituição de educação profissional podemos utilizar a Dimensão 4 Oportunidade de crescimento e segurança - com seus indicadores: 1) Possibilidade de Carreira; 2) Crescimento Pessoal; 3) Perspectiva de Avanço Salarial e; 4) Segurança de Emprego. O indicador Possibilidade de Carreira pode ser medido em empresas que utilizam cada vez mais as ferramentas tecnológicas para seleção, treinamento e desempenho de tarefas de maneira remota (ZANATTA, 2020). Assim, o aluno que tem a possibilidade aprender a utilização de uma ferramenta tecnológica de ampla utilização no mercado e estudar com o auxílio dela tem possibilidade de carreira e oportunidade de crescimento indicando melhora na Qualidade de Vida do aluno.

Diante disso, podemos estabelecer a seguinte proposição: a gestão da tecnologia melhora a qualidade de vida do aluno.

\section{METODOLOGIA}

Segundo Lakatos (2003), por meio de uma metodologia, traça-se linha de raciocínio e métodos a serem seguidos ao decorrer da pesquisa. Permite que com segurança e economia se alcance o objetivo de final, sinalizando erros e ajudando nas tomadas de decisão quanto a caminhos ou maneiras de prosseguir com a pesquisa científica.

Esta pesquisa será explanatória, tendo em vista que o conhecimento sobre o tema é vasto, porém nesta pesquisa iremos ampliar este conhecimento, pois não há muitas pesquisas específicas a respeito de como a gestão influencia a qualidade de vida. A abordagem de pesquisa é teórico-empírica e irá relacionar a realidade observada entre os alunos das escolas estaduais de ensino técnico em escolas estaduais de ensino técnico com os fundamentos teóricos das pesquisas bibliográficas (DEMO, 2000). Esta pesquisa é de lógica indutiva, porque através da teoria pesquisada e dos resultados alcançados com a aplicação do questionário poderemos confirmar ou não se a gestão da tecnologia melhora a qualidade de vida do aluno e finalmente chegar às considerações finais.

RC: 88707

Disponível em: https://www.nucleodoconhecimento.com.br/educacao/vida-de-estudantes 
Podemos entender também que esta pesquisa é qualitativa devido ao foco ser na compreensão de um grupo social e organizações (YIN, 2010). A pesquisa qualitativa pode oferecer informações relevantes sobre o estudo realizado com alunos em escolas técnicas. Ainda, pode ser considerada uma pesquisa qualitativa por ser indutiva começando com o estudo da teoria para realizar proposições aliadas com a pesquisa do tema. Com estes métodos é possível um estudo um pouco mais aprofundado do problema levantado (GIL, 2002). A partir do problema de pesquisa levantado verifica-se que a utilização do método qualitativo é o que mais se adequa, pois é a partir do problema que poderá explorar se é possível que a Gestão da Tecnologia melhore a Qualidade de vida de alunos durante uma crise sanitária.

\subsection{ESTRATÉGIA DE PESQUISA}

Nesta pesquisa foi realizada uma revisão da literatura sobre Gestão, Tecnologia e Qualidade de Vida buscando teorias que fornecessem base para a formulação da proposição "A Gestão da Tecnologia Influencia a Qualidade de Vida". A figura 1 mostra o desenho de pesquisa e ilustra a maneira indutiva de condução deste trabalho. As teorias sobre Gestão e Tecnologia mostram que a união e aplicação destes dois construtos podem levar à qualidade de vida.

O estudo de caso utilizado para verificação do fenômeno foi a gestão da tecnologia aplicada às escolas técnicas do estado de São Paulo - ETEC. Durante a crise sanitária de 2019 e 2020 o Governo do Estado de São Paulo juntamente com o Centro Paula e Souza utilizaram uma ferramenta tecnológica utilizada em larga escala entre as empresas para a manutenção das aulas no período de crise sanitária (MACEDO, 2020).

RC: 88707

Disponível em: https://www.nucleodoconhecimento.com.br/educacao/vida-de-estudantes 
Figura 1 - Desenho de Pesquisa

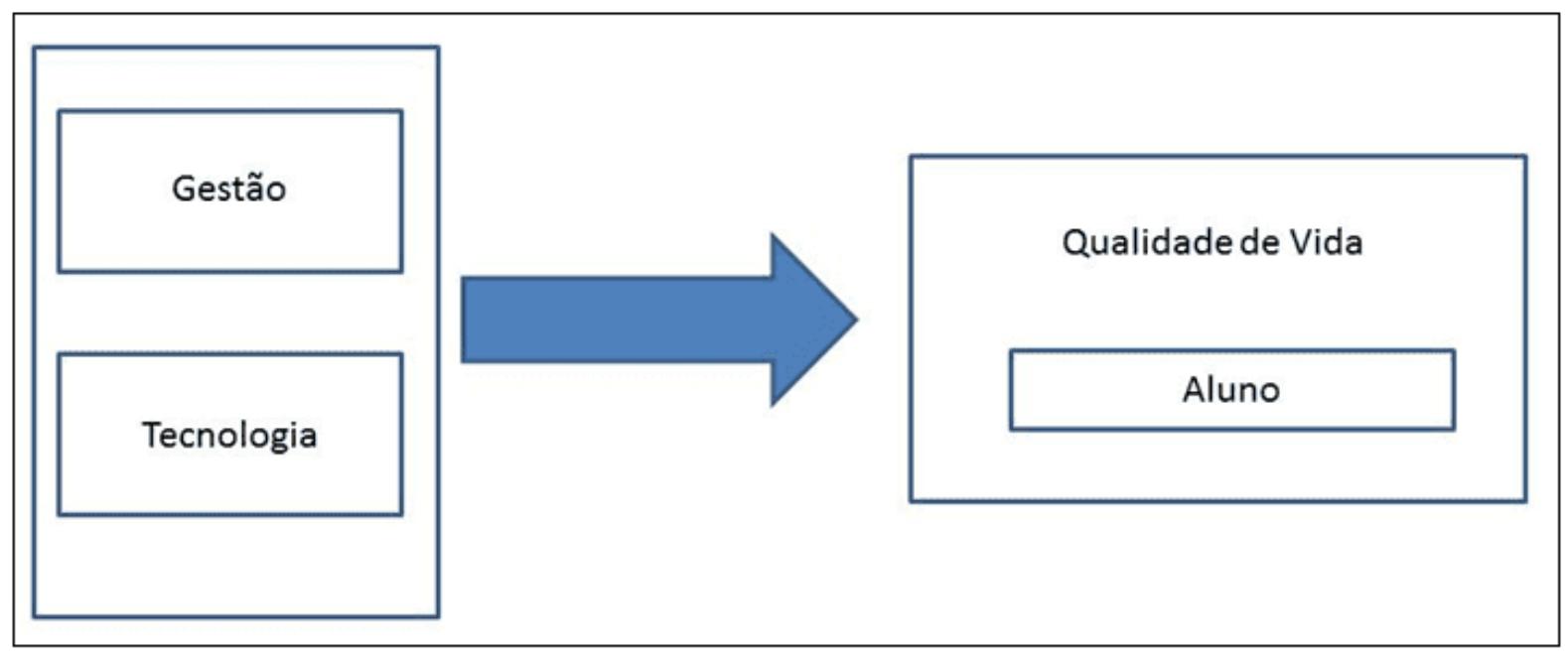

Fonte: Elaborado pelos autores

O questionário buscou verificar se os alunos conhecem ferramentas tecnológicas utilizadas em larga escala no mercado de trabalho e se eles percebiam melhora na qualidade de vida por terem aprendido a trabalhar com a ferramenta e possibilitar o acesso a vagas de empregos em empresas que utilizam estas ferramentas para seleção de funcionários e no trabalho diário. Além disso, foi possível verificar como os alunos qualificam seus equipamentos e acesso à internet já que este também é um pré-requisito cada vez mais presente nas organizações conforme Zanatta (2020).

\section{APRESENTAÇÃO E DISCUSSÃO DE RESULTADOS}

As perguntas do questionário foram baseadas nos indicadores da Dimensão 4 do Quadro 1 - Dimensões de QVT segundo o modelo de Walton (1973). Além disso, o questionário buscou trazer dados que pudessem gerar informações sobre o perfil dos respondentes. Todos são matriculados em duas escolas técnicas do Estado de São Paulo - ETEC. Foi realizado um questionário no Microsoft Forms com sete (07) perguntas fechadas e obtidas cinquenta e sete (57) respostas por formulário Forms

RC: 88707

Disponível em: https://www.nucleodoconhecimento.com.br/educacao/vida-de-estudantes 
para duas escolas. Os formulários estão armazenados em nuvem e disponíveis para acesso com os autores.

Os respondentes são predominantemente da faixa etária até 18 anos e tem e em seus lares possuem entre 4 e 5 pessoas compondo o ambiente que vivem. Classificam seus equipamentos e acesso à internet como Bom e Regular.

Sobre o conhecimento de ferramentas tecnológicas utilizadas no mercado de trabalho, a maior parte dos alunos selecionou a Ferramenta Teams como uma ferramenta de seu conhecimento, mas uma pequena parte selecionou a ferramenta Zoom e Skype.

Sobre os benefícios diretos que uma ferramenta tecnológica pode trazer, a maior parte dos alunos respondeu que elas permitem maior acesso aos conteúdos didáticos e maior produtividade durante as aulas.

Foram realizadas duas perguntas sobre a ferramenta tecnológica relacionada com Qualidade de Vida: 1) "Você acredita que a utilização de uma ferramenta tecnológica pode trazer qualidade de vida?" e; 2) "Você acredita que aprender a trabalhar com uma ferramenta de tecnologia pode trazer diferencial competitivo no mercado de trabalho?". Para a primeira pergunta os respondentes em sua maioria classificaram que uma ferramenta tecnológica pode trazer qualidade de vida. Acreditam plenamente que a utilização de uma ferramenta tecnológica pode trazer qualidade de vida $33 \%$ dos entrevistados e acreditam parcialmente que a utilização de uma ferramenta tecnológica pode trazer qualidade de vida $63 \%$ dos entrevistados conforme o Gráfico 1. Já para a segunda pergunta - Gráfico 2 - $56 \%$ responderam que acreditam plenamente que aprender a trabalhar com uma ferramenta tecnológica pode trazer diferencial competitivo no mercado de trabalho e $38 \%$ acreditam parcialmente que aprender a trabalhar com uma ferramenta tecnológica pode trazer diferencial competitivo no mercado de trabalho.

RC: 88707

Disponível em: https://www.nucleodoconhecimento.com.br/educacao/vida-de-estudantes 
Gráfico 1 - Você acredita que a utilização de uma ferramenta tecnológica pode trazer qualidade de vida?

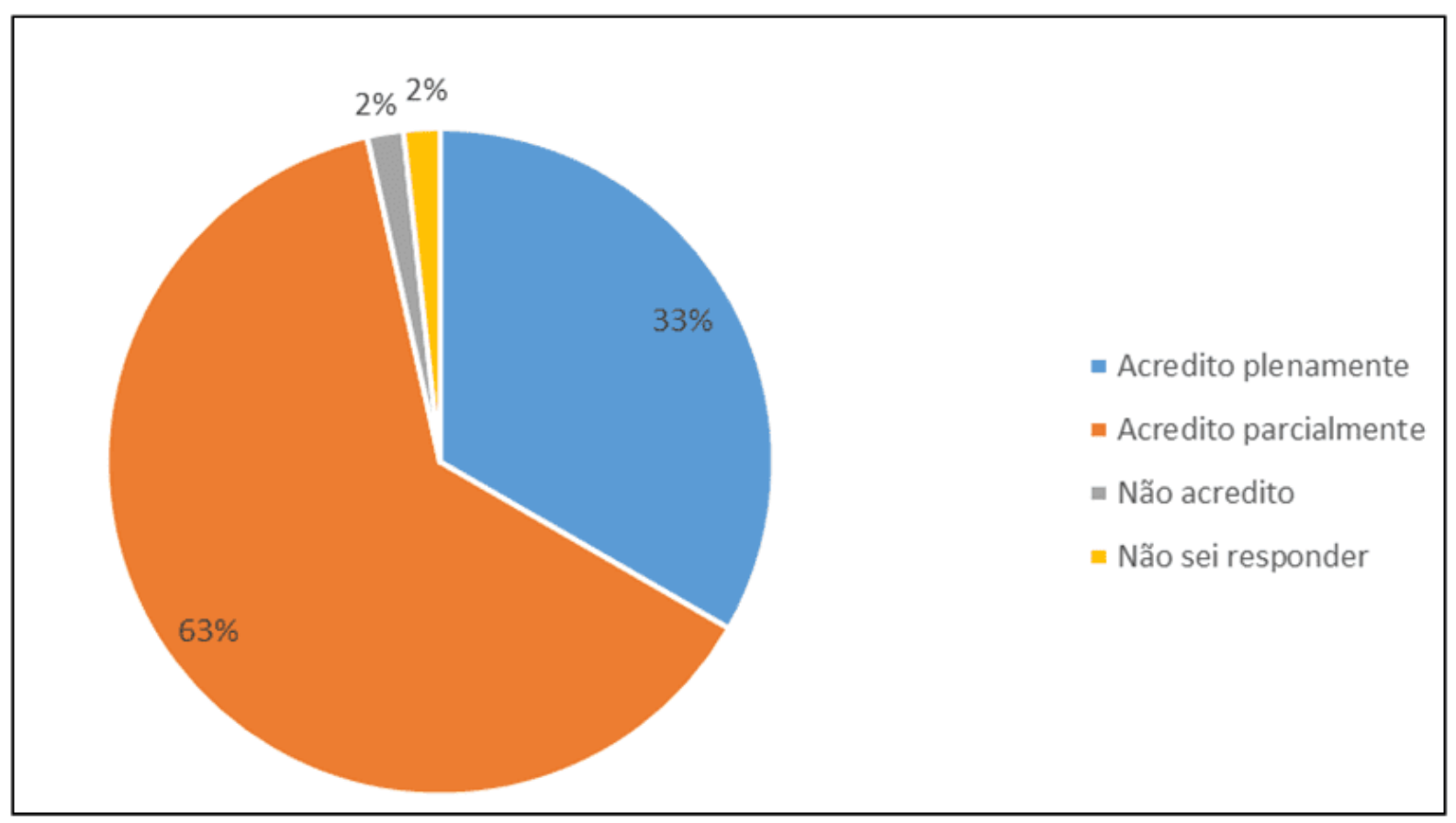

Fonte: elaborado pelos autores

RC: 88707

Disponível em: https://www.nucleodoconhecimento.com.br/educacao/vida-de-estudantes 
Gráfico 2 - Você acredita que aprender a trabalhar com uma ferramenta de tecnologia pode trazer diferencial competitivo no mercado de trabalho?

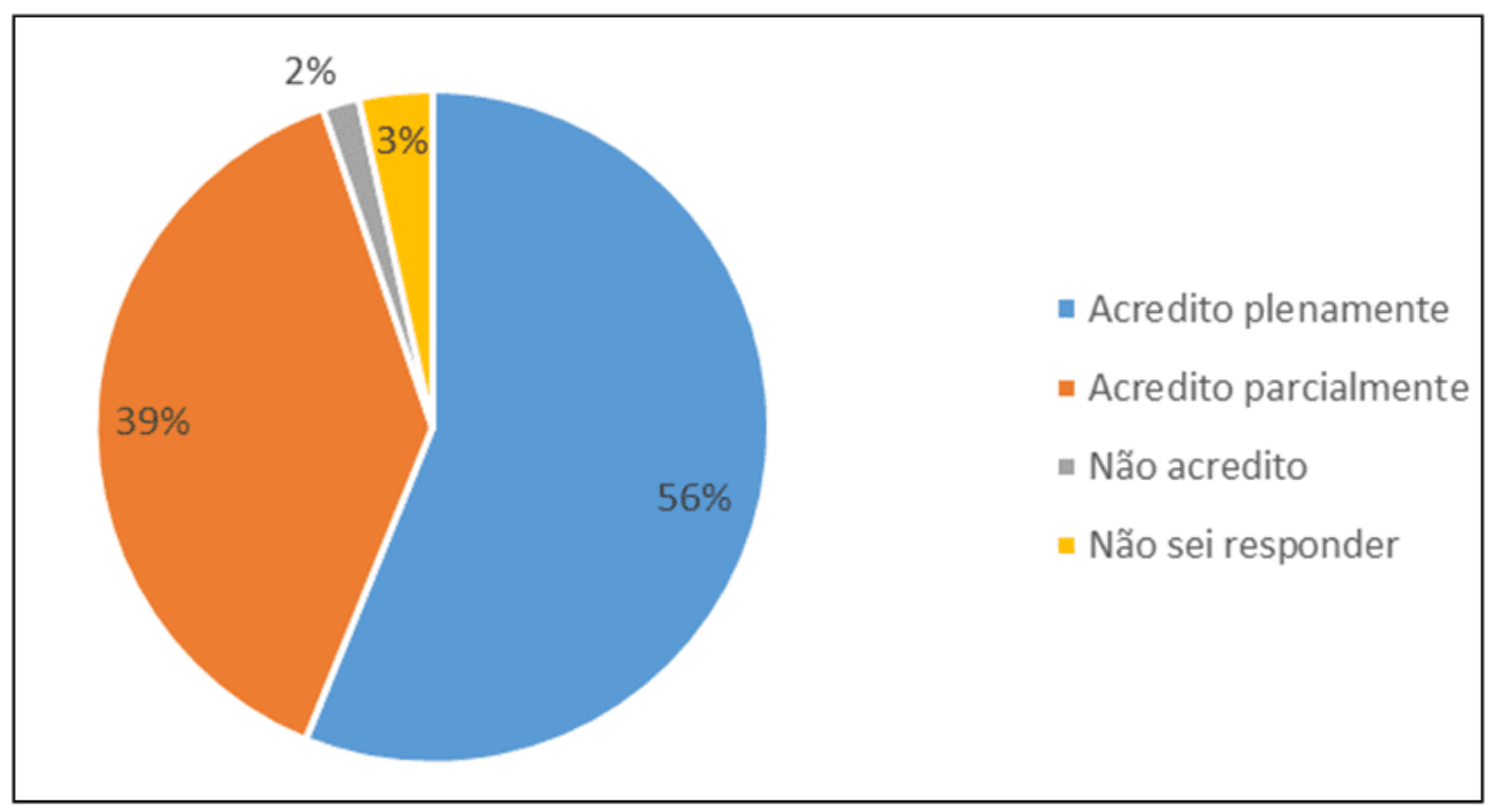

Fonte: elaborado pelos autores

Assim, os métodos utilizados contribuíram para a resposta da pergunta desta pesquisa com a verificação do fenômeno e registro das informações obtidas no estudo de caso realizado em escolas técnicas da cidade de São Paulo. As respostas dos questionários aplicados sugerem que os alunos entendem a importância de trabalhar com ferramentas tecnológicas para a melhorar a competitividade no mercado de trabalho, mas não relacionam este fato com melhora da qualidade de vida.

\section{CONSIDERAÇÕES FINAIS}

Esta pesquisa teve como objetivo analisar como a gestão da tecnologia contribui para a melhora da qualidade de vida de alunos de escolas do ensino técnico na cidade de São Paulo - ETEC. A pergunta de pesquisa foi: É possível que a gestão da tecnologia melhore a qualidade de vida de alunos durante uma crise sanitária? Com a revisão da

RC: 88707

Disponível em: https://www.nucleodoconhecimento.com.br/educacao/vida-de-estudantes 
literatura foi possível estabelecer a proposição: A Gestão da Tecnologia Melhora a Qualidade de Vida do Aluno.

Diante disso, os construtos estudados se inter-relacionam e foi possível observar que a proposição estabelecida pode ser validada com as pesquisas já realizadas sobre Gestão, Tecnologia e Qualidade de Vida e com a observação do estudo de caso da aplicação da gestão de recursos tecnológicos no aprendizado dos alunos das escolas técnicas do Estado de São Paulo - ETEC. As respostas dos alunos mostram que eles entendem que aprender a trabalhar com uma ferramenta utilizada em larga escala por empresas gera diferencial competitivo. No entanto, quando perguntado se este aprendizado leva qualidade de vida, a percepção dos alunos não reflete o mesmo entendimento. Isso pode indicar que os alunos não têm consciência de que a possibilidade de carreira, crescimento pessoal e perspectiva de avanço são indicadores de qualidade de vida.

Ainda, foi possível observar que os alunos, mesmo utilizando uma única ferramenta tecnológica na escola, têm em suas mentes outras ferramentas utilizadas em larga escala atualmente.

A pesquisa foi realizada num período de crise econômico-sanitária no mundo e com o estudo de caso foi possível observar que os recursos tecnológicos minimizaram os efeitos indesejáveis da crise no Brasil em 2020 e a possibilidade de continuidade da modalidade remota no ensino técnico pode continuar levando qualidade de vida aos alunos das escolas técnicas em acordo com as metas estabelecidas pela ONU, que promove vida saudável e bem-estar para as pessoas do mundo, mesmo após o período pandêmico.

Este estudo pode ser ampliado para um número maior de respondentes o que levará a maior precisão na análise final. Outra limitação foi a aplicação do questionário em um pequeno número de escolas. Um estudo segmentado por regiões da cidade de São Paulo e interior do Estado pode ser uma sugestão para estudos futuros.

RC: 88707

Disponível em: https://www.nucleodoconhecimento.com.br/educacao/vida-de-estudantes 


\section{REFERÊNCIAS}

ALBUQUERQUE, L. G.; LIMONGI-FRANÇA, A. C. Estratégias de recursos humanos e Gestão da Qualidade de Vida no Trabalho: o stress e a expansão do conceito de qualidade total. Revista de Administração, v. 33, n. 2, p. 40-51, 1998.

ALPERSTEDT, G. D.; MARTIGNAGO, G.; FIATES, G. G. S. O processo de adaptação estratégica em uma instituição de ensino superior sob a ótica da Teoria Institucional. Revista de Ciências da Administração, v. 8, n. 15, p. 114-137, 2006.

BARNEY, J. B.; HESTERLY, W. S. Administração Estratégica e Vantagem Competitiva: conceitos e casos. 3. ed. São Paulo: Pearson Prentice Hall. p.408, 2011.

BARNEY, J. Firm Resources and Sustained Competitive Advantage. Journal of Management v. 17, n. 1, p. 99-120, 1991.

CHAVES, Eduardo. Tecnologia e educação: o futuro da escola na sociedade da informação. Campinas. PBR Informática Ltda. 1998. Disponível em: < https://www.researchgate.net/profile/Eduardo_Chaves/publication/327112176_Tecno logia_e_Educacao_O_Futuro_da_Escola_na_Sociedade_da_Informacao/links/5b7a9 4004585151 fd121c324/Tecnologia-e-Educacao-O-Futuro-da-Escola-na-Sociedadeda-Informacao.pdf >. Acesso em: 20 jun. 2020.

CHIAVENATO, Idalberto. Gestão de Pessoas. Ed Elsevier. Rio de Janeiro. 2010.

DEMO, Pedro. Metodologia do conhecimento científico. Atlas. São Paulo. 2000.

EVANS, P. Carreira, sucesso e qualidade de vida. Revista de Administração de Empresas, v. 36, n. 3, p. 14-22, 1996.

GIL, C. Antônio. Como elaborar projetos de pesquisa. Ed Atlas. São Paulo. 2002.

RC: 88707

Disponível em: https://www.nucleodoconhecimento.com.br/educacao/vida-de-estudantes 
LAKATOS, Eva Maria; MARCONI, Marina de Andrade. Fundamentos de metodologia científica. Ed Atlas. São Paulo. 2003.

LÍRIO, A. B.; GALLON, S.; COSTA, C. Percepções da Qualidade de Vida no Trabalho nas Diferentes Gerações. Gestão \& Regionalidade, v. 36, n. 107, p. 201-220, 2020.

MACEDO. Faustolo. Legado da covid-19 para a educação brasileira. Disponível em: < https://politica.estadao.com.br/blogs/fausto-macedo/legado-da-covid-19-paraa-educacao-brasileira/ >. Acesso em 23 jun.2020.

ONU. ODS3. Saúde e Bem-Estar. Disponível em < https://nacoesunidas.org/pos2015/ods3/ >. Acesso em: 22 jun.2020.

PORTER, M. E. The Competitive Advantage: Creating and Sustaining Superior Performance. [S.I.]: Elsevier, 1985. 512 p. .

PORTER, Michael Eugene. Clusters and the New Economics of Competition. 1998a.

SALTONSTALL, Robert. Who's who in personnel administration. Ed Harvard Business Review. p.64

SILVA, G. Cylon; MELO, Lucia. Ciência, Tecnologia e Inovação: Desafio para a sociedade brasileira. Brasília: Ministério da Ciência e Tecnologia, 2001.

SILVA, M. F. G. Uma História sobre Pandemia (Covid-19), Isolamento e Fundamentos Microeconômicos de Políticas Públicas. Cadernos Gestão Pública e Cidadania, v. 25, n. 80, p. 1-11, 2020.

SMITH, A. A riqueza das nações. Investigação sobre sua natureza e suas causas. Volumes I e II. São Paulo: Nova Cultural, Coleção "Os economistas”, 1996. 
TIECHER, B.; DIEHL, L. Qualidade de Vida no trabalho na percepção dos bancários. Pensamento \& Realidade, v. 32, n. 1, p. 41-60, 2017.

VIZEU, F. (Re)contando a Velha História: reflexões sobre a gênese do management. Revista de Administração Contemporânea, v. 14, n. 5, art. 1, p. 780-797, 2010.

WALTON, R. E. Quality of work life: what is it? Sloan Management Review. Cambridge, v. 15, n. 1, p. 11-21, 1973.

YIN, R. K. Estudo de caso: planejamento e métodos. Ed Porto Alegre: Bookman, 2010.

ZANATTA, B. Novos contratados fazem integração $100 \%$ remota em tempos de pandemia. Disponível em: < https://economia.estadao.com.br/blogs/radar-doemprego/novos-contratados-fazem-integracao-100-remota-em-tempos-de-pandemia/ $>$ Acesso em 8 jun.2020.

Enviado: Novembro, 2020.

Aprovado: Junho, 2021.

RC: 88707

Disponível em: https://www.nucleodoconhecimento.com.br/educacao/vida-de-estudantes 